\title{
ANALISIS EFISIENSI ALOKATIF PENGGUNAAN FAKTOR-FAKTOR PRODUKSI PADA USAHATANI TANAMAN HIAS DRACAENA UNTUK PASAR EKSPOR DI KABUPATEN SUKABUMI
}

\author{
${ }^{1}$ Yayan Rismayanti, Dini Rochdiani dan ${ }^{2}$ Lies Sulistyowati \\ ${ }^{1}$ Mahasiswa Program Studi Ekonomi Pertanian Fakultas Pertanian, Universitas Padjadjaran \\ ${ }^{2}$ Dosen Program Studi Agribisnis Fakultas Pertanian Universitas Padjadjaran \\ Email: yayan.rismayanti@gmail.com
}

\begin{abstract}
Abstrak
Penelitian ini bertujuan untuk mengidentifikasi faktor-faktor yang dapat mempengaruhi jumlah produksi tanaman hias Dracaena dan menganalisis tingkat efisiensi alokatif penggunaan faktor produksi usahatani tanaman hias Dracaena di Kabupaten Sukabumi. Penelitian ini dilakukan di Kabupaten Sukabumi sebagai sentra tanaman hias Dracaena terbesar di Provinsi Jawa Barat pada bulan Januari sampai Juni 2018. Penelitian dilakukan dengan metode survey dengan pengambilan sampel secara simple random sampling. Penelitian dilakukan terhadap 35 orang petani tanaman hias Dracaena di Kabupaten Sukabumi dengan tujuan pasar ekspor. Data yang dikumpulkan dianalisis dengan menggunakan analisis faktor-faktor yang berpengaruh terhadap jumlah produksi tanaman hias Dracaena menggunakan analisis fungsi produksi dan analisis efisiensi penggunaan faktor-faktor produksi usahatani. Hasil penelitian menunjukkan bahwa faktor produksi yang berpengaruh signifikan terhadap jumlah produksi tanaman hias Dracaena di Kabupaten Sukabumi adalah luas lahan, benih, dan tenaga kerja dimana kenaikan atau penurunan penggunaan ketiga faktor produksi tersebut akan mengakibatkan kenaikan atau penurunan jumlah produksi Dracaena. Pengalokasian faktor produksi luas lahan, benih, pestisida, dan tenaga kerja pada usahatani tanaman hias Dracaena di Kabupaten Sukabumi belum efisien sehingga penggunaannya perlu ditambahkan untuk mencapai efisien, sedangkan penggunaan faktor produksi pupuk pada usahatani tanaman hias Dracaena tidak efisien sehingga penggunaannya perlu dikurangi.
\end{abstract}

Kata Kunci: efisiensi alokatif, faktor produksi usahatani, tanaman hias Dracaena

\begin{abstract}
This study aims to identify the factors that can affect the amount of Dracaena ornamental plant production and analyze the level of allocative efficiency of the use of Dracaena ornamental plant farming production factors in Sukabumi Regency. This research was conducted in Sukabumi Regency as the largest Dracaena ornamental plant center in West Java Province in January to June 2018. The research was conducted by survey method by sampling using simple random sampling. The study was conducted on 35 Dracaena ornamental plant farmers in Sukabumi Regency with the aim of the export market. The data collected was analyzed using the analysis of factors that influence the amount of ornamental plant production Dracaena used an analysis of production functions and an analysis of the efficiency of the use of farm production factors. The results showed that the factors of production that had a significant effect on the amount of production of Dracaena ornamental plants in Sukabumi Regency were land area, seeds, and labor where the increase or decrease in the use of the three production factors would result in an increase or decrease in the amount of Dracaena production. Allocation of production factors for land area, seeds, pesticides, and labor in Dracaena ornamental plant farming in Sukabumi Regency has not been efficient so that their use needs to be added to achieve efficiency, while the use of fertilizer production factors in Dracaena ornamental plant farming is inefficient so their use needs to be reduced.
\end{abstract}

Keywords: allocative efficiency, farming production factors, Dracaena ornamental plants 


\section{Pendahuluan}

Komoditas tanaman hias atau florikultura merupakan salah satu subsektor yang memiliki potensi sebagai pusat pertumbuhan baru sektor pertanian. Florikultura di Indonesia terus dikembangkan menjadi salah satu industri yang diharapkan dapat meningkatkan kesejahteraan petani, memperluas lapangan pekerjaan, pariwisata, serta menciptakan lingkungan yang sehat dan nyaman. Saat ini perkembangan komoditas tanaman hias sangat pesat, dari mulai pinggir jalan sampai perusahaan besar. Hal ini sebagai dampak dari kesadaran masyarakat akan keindahan lingkungan, baik di luar maupun di dalam ruangan. Penjualan tanaman hias sangat menjanjikan keuntungan yang cukup besar. Selain itu, adanya fluktuasi volume ekspor juga menunjukkan bahwa terdapat peluang usaha yang menjanjikan untuk mengembangkan usahatani tanaman hias (Tamam dan Soedjatmiko, 2006).

Kementerian Pertanian telah menetapkan bahwa terdapat delapan komoditas tanaman hias dalam negeri yang memiliki nilai ekspor tinggi yaitu Krisan, Anggrek, Melati, Raphis, Leatherleaf, Heliconia, tanaman hias taman, dan Dracaena. Fokus Pemerintah terhadap delapan jenis komoditas tersebut bertujuan untuk meningkatkan pendapatan petani dan daya saing produk florikultura. Pembangunan agribisnis florikultura mencatat berbagai keberhasilan selama periode 2010-2016, diantaranya peningkatan produksi, produktivitas, luas area tanam, nilai ekspor, dan penyerapan tenaga kerja. Pada periode waktu tersebut, produksi dan produktivitas berbagai komoditas florikultura rata-rata meningkat sekitar $27 \%$ per tahun, luas tanam meningkat $15 \%$ per tahun, nilai PDB florikultura meningkat $12 \%$, nilai ekspor mencapai lebih dari US\$ 20 juta, dan penyerapan tenaga kerja mencapai lebih dari
0,75 juta orang

(http://hortikultura.pertanian.go.id, 2017).

Dracaena merupakan salah satu jenis tanaman hias perdu tegak dengan helai daun yang indah, mudah dibudidayakan, dan memiliki peluang pasar ekspor. Jenis tanaman hias tropis ini dapat dimanfaatkan sebagai materi taman, daun potong, sebagai hiasan dalam ruangan (indoor plant), dan dapat dirangkai dengan desain artistik menjadi dekorasi pada pesta maupun acara tertentu. Dracaena tergolong dalam famili Lyliaceae yang berfungsi sebagai penyerap polusi udara misalnya $\mathrm{NO}_{2}$ yang mencemari udara. Berdasarkan hasil pengumpulan dan pengolahan data SPH pada tahun 2013, pada kelompok daun potong, Dracaena merupakan tanaman yang mempunyai kontribusi produksi terbesar yaitu 2.887.745 pohon $(84,79 \%)$ terhadap total produksi daun potong di Indonesia (Direktorat Jenderal Hortikultura, 2014). Provinsi Jawa Barat merupakan penghasil Dracaena terbesar di Indonesia dengan produksi pada tahun 2014 yaitu 3.132.974 pohon $(88,73 \%)$ dari total produksi Dracaena nasional (Direktorat Jenderal Hortikultura, 2015).

Dracaena memiliki potensi besar terutama di pasar ekspor sehingga membutuhkan pengembangan yang intensif. Produk rangkaian Dracaena, khususnya Dracaena sanderiana dari Kabupaten Sukabumi sudah diekspor ke berbagai negara seperti Arab Saudi, Rusia, Uzbekistan, Iran, Singapura, Azerbaijan, Jepang, dan Korea (Direktorat Budidaya dan Pascapanen Florikultura, 2015). Akan tetapi, potensi pasar yang demikian besar belum didukung oleh luas panen dan produksi yang memadai sehingga masih harus mendatangkan produk Dracaena dari luar daerah untuk memenuhi kuota ekspor. Hal tersebut digambarkan oleh perkembangan luas panen Dracaena di Kabupaten Sukabumi yang masih berfluktuasi selama 10 tahun terakhir. Perkembangan luas panen Dracaena pada 
tahun 2005-2015 di Kabupaten Sukabumi dapat dilihat pada Gambar 1.

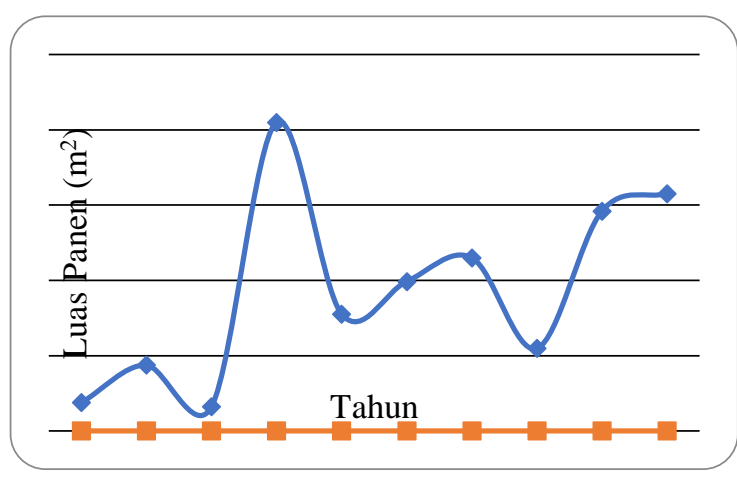

\section{Gambar 1}

Perkembangan Luas Panen Dracaena Tahun 2005-2015 di Kabupaten Sukabumi (Sumber: Badan Pusat Statistik Provinsi Jawa Barat, 2006-2016)

Produktivitas Dracaena di Kabupaten Sukabumi selama 10 tahun terakhir cukup berfluktuasi (Gambar 2). Hal tersebut diperkirakan terjadi akibat alokasi penggunaan faktor-faktor produksi yang belum efisien. Gejala penggunaan faktorfaktor produksi yang belum efisien ditunjukkan oleh produktivitas usahatani yang bervariasi setiap tahun bahkan pada posisi luas panen yang hampir sama. Efisiensi merupakan faktor yang sangat penting di negara berkembang untuk menentukan pertumbuhan produktivitas, dimana sumber daya yang terbatas dan kurangnya kesempatan dalam melakukan pengembangan dan melakukan adopsi teknologi yang baik (Bifarin et al, 2010).

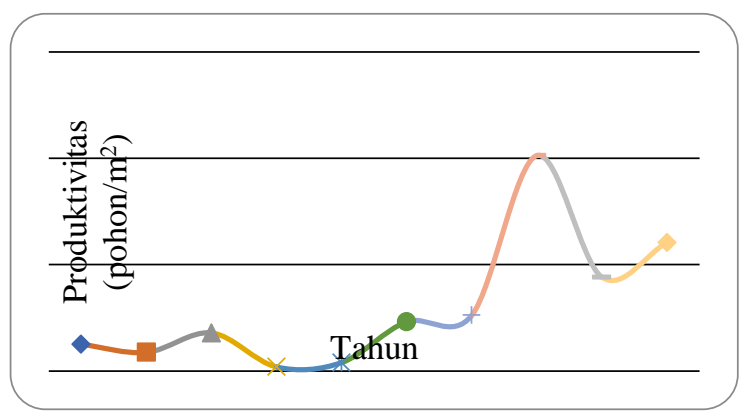

\section{Gambar 2. Perkembangan Produktivitas Dracaena Tahun 2005-2015 di Kabupaten Sukabumi (Sumber: Badan Pusat Statistik Provinsi Jawa Barat, 2006-2016)}

Beberapa permasalahan usahatani yang dihadapi oleh petani produsen Dracaena di Kabupaten Sukabumi sebagai sentra produksi Dracaena terbesar di Jawa Barat antara lain: lahan penanaman Dracaena masih terpencar dalam skala-skala kecil dan terbatas, tidak terdapat lahan atau hamparan khusus untuk pertanaman Dracaena, masih kurangnya benih tanaman Dracaena baik secara kuantitas maupun kualitas untuk memenuhi kuota ekspor, terdapat serangan penyakit pada musim penghujan yang dapat menurunkan kuantitas dan kualitas produksi, petani belum sepenuhnya menerapkan Good Agriculture Practices (GAP), dan penggunaan faktor-faktor produksi yang belum sesuai (Direktorat Jenderal Hortikultura, 2013; BP3K Kecamatan Sukabumi, 2017).

Secara alokatif proses produksi tidak dilakukan secara efisien jika proporsi penggunaan faktor produksi tidak optimum yang diindikasikan dengan produk penerimaan marginal yang tidak sebanding dengan biaya marginal faktor produksi yang digunakan (Tinaprilla, 2012). Penggunaan faktor produksi pada tanaman hias Dracaena antara lain lahan, benih, pupuk, pestisida, dan tenaga kerja. Apabila petani masih belum mampu mengalokasikan secara optimal semua faktor produksi yang ada dalam proses produksi usahatani Dracaena dan petani belum mengetahui faktor produksi mana yang alokasi penggunaannya sudah optimum, maka hal ini akan berpengaruh terhadap biaya produksi dan pendapatan petani. Berdasarkan latar belakang tersebut, maka tujuan penelitian ini 
adalah: 1) mengidentifikasi faktor-faktor yang dapat mempengaruhi jumlah produksi tanaman hias Dracaena di Kabupaten Sukabumi, dan 2) menganalisis tingkat efisiensi alokatif penggunaan faktor produksi usahatani tanaman hias Dracaena di Kabupaten Sukabumi.

\section{Metode Penelitian}

Penelitian ini dilakukan di Kabupaten Sukabumi sebagai sentra tanaman hias Dracaena terbesar di Provinsi Jawa Barat pada bulan Januari sampai Juni 2018. Penelitian dilakukan dengan metode survey dengan pengambilan sampel secara simple random sampling. Penelitian dilakukan terhadap 35 orang petani tanaman hias Dracaena di Kabupaten Sukabumi dengan tujuan pasar ekspor. Metode analisis data yang digunakan dalam penelitian ini sebagai berikut:

a. Analisis faktor-faktor yang berpengaruh terhadap jumlah produksi tanaman hias Dracaena

Alat yang digunakan untuk menganalisis faktor-faktor yang berpengaruh terhadap jumlah produksi tanaman hias Dracaena adalah analisis fungsi produksi. Fungsi yang digunakan dalam penelitian ini adalah model fungsi produksi Cobb-Douglas yang dapat dituliskan sebagai berikut:

$Y=\beta_{0} X_{1}^{\beta 1} X_{2}^{\beta 2} X_{3}^{\beta 3} X_{4}^{\beta 4} X_{5}^{\beta 5} e^{u}$

Model fungsi produksi CobbDouglas tersebut ditranformasikan ke dalam bentuk double logaritma natural (Ln), sehingga merupakan bentuk linear berganda sebagai berikut:

$$
\begin{aligned}
& \operatorname{LnY}=\beta_{0}+\beta_{1} \operatorname{LnX}_{1}+\beta_{2} \operatorname{LnX}_{2}+ \\
& \beta_{3} \operatorname{LnX} 3+\beta_{4} \ln X_{4}+\beta_{5} \operatorname{LnX}_{5}+u
\end{aligned}
$$$$
\text { (2) }
$$

Dimana: $\beta_{0}=$ Intersep $/$ Konstanta

$\beta_{1} \ldots, \beta_{5}=$ Elastisitas produksi

$\mathrm{Y}=$ Jumlah produksi Dracaena (pohon)

$\mathrm{X}_{1}=$ Luas lahan $\left(\mathrm{m}^{2}\right)$

$\mathrm{X}_{2}=$ Jumlah benih Dracaena (batang)

$\mathrm{X}_{3}=$ Jumlah pupuk $(\mathrm{kg})$

$\mathrm{X}_{4}=$ Jumlah pestisida (liter)

$\mathrm{X}_{5}=$ Jumlah tenaga kerja yang digunakan (HOK)

$\mathrm{u}=$ Kesalahan (disturbance terms)

$\mathrm{e}=$ Bilangan natural $(\mathrm{e}=2,718)$

b. Analisis efisiensi alokatif penggunaan faktor-faktor produksi pada usahatani Dracaena

Efisiensi alokatif dapat dianalisis dengan cara membandingkan nilai produk marginal $\left(\mathrm{NPM}_{\mathrm{xi}}\right)$ dan harga input tersebut $\left(\mathrm{P}_{\mathrm{xi}}\right)$. Secara matematis dapat dituliskan sebagai berikut:

$\mathrm{NPM}_{\mathrm{xi}}=\mathrm{b}_{\mathrm{i}} \frac{\mathrm{Y}}{\mathrm{X}_{\mathrm{i}}} \cdot \mathrm{P}_{\mathrm{y}} \mathrm{NPM}_{\mathrm{xi}}=\mathrm{PM}_{\mathrm{xi}} \cdot \mathrm{P}_{\mathrm{y}}$

Keterangan:

$\mathrm{NPM}_{\mathrm{xi}}=$ Nilai produk marginal faktor produksi ke-i

$\mathrm{PM}_{\mathrm{xi}}=$ Produk marginal faktor produksi ke-i

$b_{\mathrm{i}} \quad=$ Koefesien regresi $\mathrm{X}_{\mathrm{i}}$

$\mathrm{X}_{\mathrm{i}}=$ Rata-rata penggunaan faktor produksi Dracaena ke-i

$\mathrm{Y}=$ Rata-rata produksi Dracaena (pohon)

$\mathrm{P}_{\mathrm{xi}} \quad=$ Rata-rata harga faktor produksi Dracaena ke-i (Rp)

$\mathrm{P}_{\mathrm{y}} \quad=$ Rata-rata harga satuan hasil produksi Dracaena $(\mathrm{Rp})$ 
Pada banyak kenyataan $\mathrm{NPM}_{\mathrm{xi}}$ tidak selalu sama dengan $\mathrm{P}_{\mathrm{xi}}$, yang sering terjadi adalah (Nicholson, 1995):

a. $\frac{\mathrm{NPM}_{\mathrm{xi}}}{\mathrm{P}_{\mathrm{xi}}}>1$; artinya penggunaan faktor produksi xi belum efisien dan belum mencapai batas penggunaan faktor produksi secara optimal untuk mencapai efisien, maka penggunaan faktor produksi xi perlu ditambah.

b. $\frac{\mathrm{NPM}_{\mathrm{xi}}}{\mathrm{P}_{\mathrm{xi}}}<1$; artinya penggunaan faktor produksi tidak efisien dan sudah melewati batas penggunaan faktor produksi secara optimal untuk mencapai efisien, maka faktor produksi xi perlu dikurangi.

\section{Hasil dan Pembahasan}

\section{Karakteristik Lokasi Penelitian}

Kecamatan Sukabumi dan Kecamatan Sukaraja merupakan dua dari 47 kecamatan yang terdapat di Kabupaten Sukabumi. Batas wilayah Kecamatan Sukabumi adalah: sebelah utara Kota Sukabumi, sebelah selatan Kecamatan Kadudampit, sebelah timur Kecamatan Sukaraja, sebelah barat Kota Sukabumi. Sedangkan Kecamatan Sukaraja berbatasan dengan: sebelah utara Kecamatan Sukabumi, sebelah selatan Kecamatan Kebonpedes, sebelah timur Kecamatan Sukalarang, dan sebelah barat Kota Sukabumi. Kecamatan Sukabumi memiliki ketinggian 500 - 1.000 m dpl, sedangkan ketinggian Kecamatan Sukaraja 500 - 1.200 m dpl (Badan Pusat Statistik Kabupaten Sukabumi, 2017).

Kecamatan Sukabumi memiliki potensi usahatani seperti tanaman pangan, hortikultura, dan peternakan. Komoditas hortikultura yang menjadi unggulan di Kecamatan Sukabumi adalah tanaman sayuran dan tanaman hias dimana salah satunya adalah Dracaena. Komoditas unggulan pertanian di Kecamatan Sukaraja antara lain tanaman pangan dan hortikulura. Komoditas tanaman hias didominasi oleh Krisan dan hanya sebagian kecil petani yang mengusahakan tanaman Dracaena.

Dracaena merupakan komoditas unggulan yang ditanam di daerah penelitian karena budidaya yang cukup mudah, pemeliharaan tidak merepotkan, dan terdapat kejelasan pasar. Adapun kekurangan dari usahatani Dracaena yang dirasakan petani adalah masa awal panen yang cukup lama mencapai 1 tahun, pemanenan tidak seragam untuk waktu penanaman yang sama, dan walaupun terdapat kejelasan pasar untuk orientasi ekspor tetapi petani belum memperoleh imbalan yang sesuai dengan korbanan yang dikeluarkan.

\section{Faktor-faktor yang Mempengaruhi Jumlah Produksi Tanaman Hias Dracaena}

Hasil uji $\mathrm{F}$ menunjukkan bahwa terdapat pengaruh yang signifikan antara luas lahan, benih, pupuk, pestisida, dan tenaga kerja secara simultan terhadap jumlah produksi Dracaena. Hasil analisis regresi linear berganda untuk pengaruh penggunaan faktor-faktor produksi terhadap jumlah produksi Dracaena dapat dilihat pada Tabel 1.

Tabel 1

Hasil Analisis Regresi Linear Berganda

\begin{tabular}{lcccc} 
Variabel & $\begin{array}{c}\text { Koefisi } \\
\text { en } \\
\text { Regresi }\end{array}$ & $\mathrm{t}$ & Sig. & Ket. \\
\hline (Constant) & 2,162 & 3,189 & 0,003 & \\
\hline Luas lahan & 0,207 & 2,218 & 0,035 & $\begin{array}{c}\text { Signifika } \\
\mathrm{n}\end{array}$ \\
\hline Benih & 0,697 & 7,999 & 0,000 & $\begin{array}{c}\text { Signifika } \\
\mathrm{n}\end{array}$ \\
\hline Pupuk & $-0,044$ & $-0,853$ & 0,401 & $\begin{array}{c}\text { Tidak } \\
\text { Signifika } \\
\mathrm{n}\end{array}$ \\
\hline Pestisida & 0,020 & 0,937 & 0,356 & $\begin{array}{c}\text { Tidak } \\
\text { Signifika } \\
\mathrm{n}\end{array}$ \\
\hline Tenaga kerja & 0,312 & 2,644 & 0,013 & $\begin{array}{c}\text { Signifika } \\
\mathrm{n}\end{array}$ \\
\hline
\end{tabular}


Berdasarkan Tabel 1 dapat dilihat hasil koefisien regresi $(\beta)$ dan diperoleh persamaan regresi linear berganda sebagai berikut:

$$
\begin{aligned}
\mathrm{Y}= & 2,162+0,207 \mathrm{X}_{1}+0,697 \mathrm{X}_{2}-0,044 \mathrm{X}_{3}+ \\
& 0,020 \mathrm{X}_{4}+0,312 \mathrm{X}_{5}+\mathrm{u}
\end{aligned}
$$

Hasil analisis fungsi produksi menunjukkan bahwa variabel luas lahan, benih, dan tenaga kerja secara parsial berpengaruh signifikan terhadap jumlah produksi tanaman hias Dracaena di Kabupaten Sukabumi. Nilai signifikansi untuk ketiga variabel tersebut menunjukkan nilai signifikansi yang lebih besar dari level of significance $(\alpha=0,05)$. Hal ini menunjukkan bahwa secara parsial penambahan atau penurunan penggunaan faktor produksi lahan, benih, dan tenaga kerja yang digunakan untuk usahatani tanaman hias Dracaena maka akan meningkatkan atau menurunkan jumlah produksi Dracaena.

\section{Efisiensi Alokatif Penggunaan Faktor Produksi Usahatani Tanaman Hias Dracaena}

Soekartawi (2003) mengukur tingkat produktivitas dari suatu produksi yang dilaksanakan berdasarkan dua tolak ukur yaitu produk marginal (PM) dan produk rata-rata (PR). Efisiensi alokatif adalah suatu keadaan efisiensi bila nilai dari produk marginal sama dengan harga faktor produksi yang bersangkutan. Efisiensi alokatif penggunaan faktor produksi pada usahatani Dracaena di Kabupaten Sukabumi dapat diketahui dengan menghitung rasio NPM suatu faktor produksi dengan harga masingmasing faktor produksi. Perhitungan yang digunakan untuk analisis efisiensi alokatif faktor-faktor produksi mencantumkan nilai koefisien regresi yang berasal dari fungsi produksi Cobb-Douglas (Tabel 1). Hasil analisis efisiensi alokatif dari rata-rata penggunaan faktor produksi pada usahatani
Dracaena di Kabupaten Sukabumi dapat dilihat pada Tabel 2.

\section{Tabel 2}

Analisis Efisiensi Alokatif Penggunaan Faktor-faktor Produksi Usahatani Tanaman Hias Dracaena di Kabupaten

\begin{tabular}{|c|c|c|c|c|c|c|c|c|}
\hline $\begin{array}{c}\text { Variabe } \\
1\end{array}$ & bi & $\mathrm{Y}$ & Py & $\mathrm{x}$ & Px & PMx & NPMx & $\frac{\mathrm{NPM}_{4}}{\mathrm{P}_{\mathrm{xi}}}$ \\
\hline $\begin{array}{l}\text { Luas } \\
\text { lahan }\end{array}$ & 0,207 & $\begin{array}{r}262.5 \\
90 \\
\end{array}$ & $\begin{array}{r}15 \\
0\end{array}$ & 985,7143 & 5.000 & 55,14 & 8.271 & $\begin{array}{l}1, \\
65\end{array}$ \\
\hline Benih & 0,697 & $\begin{array}{r}262.5 \\
90 \\
\end{array}$ & $\begin{array}{r}15 \\
0 \\
\end{array}$ & $\begin{array}{r}63.085,714 \\
3 \\
\end{array}$ & 50 & 2,90 & 435 & $\begin{array}{r}8 \\
70 \\
\end{array}$ \\
\hline Pupuk & 0,044 & $\begin{array}{r}262.5 \\
90\end{array}$ & $\begin{array}{r}15 \\
0\end{array}$ & $1.938,9429$ & 3.000 & $-5,96$ & -894 & $\begin{array}{r}0, \\
0, \\
30\end{array}$ \\
\hline $\begin{array}{l}\text { Pestisid } \\
\text { a }\end{array}$ & 0,020 & $\begin{array}{r}262.5 \\
90 \\
\end{array}$ & $\begin{array}{r}15 \\
0 \\
\end{array}$ & 2,6091 & $\begin{array}{r}100.0 \\
00 \\
\end{array}$ & $\begin{array}{r}2.012 \\
.88 \\
\end{array}$ & 301.932 & $\begin{array}{r}3, \\
02 \\
\end{array}$ \\
\hline $\begin{array}{l}\text { Tenaga } \\
\text { kerja }\end{array}$ & 0,312 & $\begin{array}{r}262.5 \\
90\end{array}$ & $\begin{array}{r}15 \\
0\end{array}$ & 93,1714 & $\begin{array}{r}60.00 \\
0\end{array}$ & $\begin{array}{r}879,3 \\
3\end{array}$ & $\begin{array}{r}131.899 \\
50\end{array}$ & $\begin{array}{l}2, \\
20\end{array}$ \\
\hline
\end{tabular}
Sukabumi

\section{Efisiensi Alokatif Luas Lahan}

NPMxi/Pxi di lokasi penelitian yaitu 1,65 yang berarti penggunaan faktor produksi lahan belum efisien. Nicholson (2002) menyatakan bahwa efisiensi alokatif tercapai apabila perbandingan antara nilai produktivitas marjinal masing-masing input (NPMxi) dengan harga inputnya (Pxi) sama dengan 1. Hal tersebut menunjukkan bahwa penggunaan lahan $985,7143 \mathrm{~m}^{2}$ dalam proses produksi usahatani Dracaena masih belum efisien. Oleh karena itu, agar penggunaan lahan dapat optimal maka perlu dilakukan penambahan luas lahan sehingga diharapkan dapat meningkatkan jumlah produksi dan pendapatan petani Dracaena. Hasil ini sejalan dengan hasil penelitian Sundari (2011); Mufriantie et al (2014); Suprapti et al (2014); dan Wahida et al (2015) yang menunjukkan bahwa penggunaan luas lahan belum efisien dan penggunaannya harus ditambah dengan tetap memperhatikan biaya yang digunakan.

Efisiensi Alokatif Benih 
Penggunaan benih seperti tercantum pada Tabel 2 masih belum efisien yang ditunjukkan dengan nilai NPMxi/Pxi 8,70. Hal ini menunjukkan bahwa penggunaan benih $63.085,7143$ batang untuk rata-rata luas lahan $985,7143 \mathrm{~m}^{2}$ yang ditanami petani Dracaena di lokasi penelitian masih belum efisien. Oleh karena itu, agar penggunaan benih dapat optimal maka perlu dilakukan penambahan jumlah benih yang ditanam. Penggunaan benih saat ini di tingkat petani masih terkendala oleh terbatasnya ketersediaan benih yang masih bergantung pada gudang pengrajin.

Hasil ini sejalan dengan hasil penelitian Astuti et al (2013) yang menyatakan bahwa hasil analisis efisiensi alokatif penggunaan faktor produksi benih Krisan mempunyai nilai 3,32 yang berarti penggunaan faktor produksi benih belum optimal dan usahatani bunga potong Krisan di Kabupaten Semarang belum mencapai keuntungan makimum.

\section{Efisiensi Alokatif Pupuk}

Hasil analisis diketahui NPMxi/Pxi penggunaan pupuk $-0,30$, dimana angka tersebut lebih kecil dari 1 yang menunjukkan bahwa penggunaan faktor produksi pupuk di daerah penelitian tidak efisien secara alokatif. Penggunaan pupuk $1.938,9429 \mathrm{~kg}$ untuk tanaman hias Dracaena per rata-rata luas lahan 985,7143 $\mathrm{m}^{2}$ oleh petani di Kabupaten Sukabumi diberikan secara berlebihan atau sudah melebihi batas optimal penggunaannya. Pengurangan pupuk perlu dilakukan agar penggunaan pupuk menjadi efisien sehingga dapat mengurangi biaya produksi dan meningkatkan pendapatan petani Dracaena.

Hasil ini sejalan dengan penelitian Jamalludin (2019) yang menyatakan bahwa penggunaan pupuk Urea dan dan NPK yang dialokasikan oleh petani telah berlebih atau tidak efisien sehingga petani harus mengurangi jumlah penggunaannya. Akan tetapi, hasil ini berbeda dengan penelitian Sundari (2011) dan Wahida et al (2015) yang menunjukkan bahwa jumlah penggunaan pupuk belum efisien dan menunjukkan nilai lebih dari satu, sehingga perlu adanya penambahan penggunaan pupuk.

\section{Efisiensi Alokatif Pestisida}

Penggunaan faktor produksi pestisida pada tanaman hias Dracaena di daerah penelitian seperti yang tercantum pada Tabel 2 belum efisien. Hal ini ditunjukkan dari nilai NPMxi/Pxi penggunaan pestisida 3,02 dimana angka tersebut lebih besar dari 1 yang berarti bahwa penggunaan faktor produksi belum efisien sehingga perlu dilakukan penambahan faktor produksi. Faktor produksi pestisida 2,6091 liter per $985,7143 \mathrm{~m}^{2}$ rata-rata luas lahan untuk tanaman hias Dracaena masih dapat ditambahkan agar menjadi efisien.

Hasil penelitian ini sejalan dengan Jamalludin (2019) yang menyatakan bahwa penggunaan pestisida oleh petani belum efisien sehingga jumlah pestisida yang dialokasikan harus ditambah. Hasil ini berbeda dengan penelitian Asmara et al (2013) yang menunjukkan bahwa NPMx/Px untuk alokasi penggunaan pestisida $<1$ yaitu 0,94 sehingga penggunaan pestisida tidak efisien.

\section{Efisiensi Alokatif Tenaga Kerja}

Hasil analisis diketahui NPMx/Px penggunaan tenaga kerja 2,20 dimana angka tersebut lebih besar dari 1, sehingga penggunaan tenaga kerja di daerah penelitian belum efisien. Hal ini menunjukkan bahwa penggunaan tenaga kerja 93,1714 HOK pada proses produksi usahatani Dracaena untuk rata- rata luasan lahan 985,7143 $\mathrm{m}^{2}$ di daerah penelitian belum efisien. Penambahan penggunaan tenaga kerja dapat dilakukan agar penggunaan tenaga kerja dapat optimal 
sehingga dapat meningkatkan produksi dan pendapatan petani Dracaena.

Hasil ini sejalan dengan hasil penelitian Jamalludin (2019) yang menyatakan bahwa penggunaan tenaga kerja belum efisien sehingga tenaga kerja yang dialokasikan harus ditambah. Hal berbeda dinyatakan oleh Safwan et al (2016) dan Sundari (2011) bahwa penggunaan faktor tenaga kerja sudah tidak efisien dan secara ideal harus dikurangi. Secara umum, terdapat tiga cara untuk meningkatkan produksi usahatani, yaitu: 1) meningkatkan penggunaan faktor produksi seperti lahan, tenaga kerja, dan variasi kapital, 2) menerapkan teknologi baru, dan 3) melakukan manajemen organisasi produksi dengan teknologi yang tersedia untuk meningkatkan efisiensi produksi (Li, 2000).

\section{Kesimpulan}

Faktor produksi yang berpengaruh signifikan terhadap jumlah produksi tanaman hias Dracaena di Kabupaten Sukabumi adalah luas lahan, benih, dan tenaga kerja dimana kenaikan atau penurunan penggunaan ketiga faktor produksi tersebut akan mengakibatkan kenaikan atau penurunan jumlah produksi Dracaena. Pengalokasian faktor produksi luas lahan, benih, pestisida, dan tenaga kerja pada usahatani tanaman hias Dracaena di Kabupaten Sukabumi belum efisien, sedangkan penggunaan faktor produksi pupuk pada usahatani tanaman hias Dracaena tidak efisien.

Berdasarkan hasil penelitian, saran yang dapat diberikan untuk memperoleh produksi yang efisien adalah petani Dracaena dapat melakukan penambahan luas lahan, benih, dan tenaga kerja, sedangkan penggunaan pupuk harus dikurangi.

\section{Ucapan Terimakasih}

Penulis mengucapkan terima kasih kepada BPP Kecamatan Sukabumi dan Sukaraja, kelompoktani Alamanda, dan seluruh petani tanaman hias Dracaena di Kabupaten Sukabumi yang telah berkontribusi dalam penelitian ini.

\section{Daftar Pustaka}

Astuti, T. P., Ferichani, M., dan Adi, R. K. 2013. Optimasi Penggunaan Masukan pada Produksi Bunga Potong Krisan (Crysanthenum sp.) di Kabupaten Semarang. Jurnal Sosial Ekonomi Pertanian dan Agribisnis Volume 7. Universitas Sebelas Maret.

Badan Pusat Statistik Kabupaten Sukabumi. 2017. Kabupaten Sukabumi dalam Angka 2017. Sukabumi: Badan Pusat Statistik Kabupaten Sukabumi.

Badan Pusat Statistik Provinsi Jawa Barat. 2006. Provinsi Jawa Barat dalam Angka 2006. Bandung: Badan Pusat Statistik Provinsi Jawa Barat.

Provinsi Jawa Barat dalam Angka 2007. Bandung: Badan Pusat Statistik Provinsi Jawa Barat.

2008. Provinsi Jawa Barat dalam Angka 2008. Bandung: Badan Pusat Statistik Provinsi Jawa Barat.

2010. Provinsi Jawa Barat dalam Angka 2010. Bandung: Badan Pusat Statistik Provinsi Jawa Barat.

2011. Provinsi Jawa Barat dalam Angka 2011. Bandung: Badan Pusat Statistik Provinsi Jawa Barat. 
2012. Provinsi Jawa Barat dalam Angka 2012. Bandung: Badan Pusat Statistik Provinsi Jawa Barat.

2013. Provinsi Jawa Barat dalam Angka 2013. Bandung: Badan Pusat Statistik Provinsi Jawa Barat.

2014. Provinsi Jawa Barat dalam Angka 2014. Bandung: Badan Pusat Statistik Provinsi Jawa Barat.

2015. Provinsi Jawa Barat dalam Angka 2015. Bandung: Badan Pusat Statistik Provinsi Jawa Barat.

2016. Provinsi Jawa Barat dalam Angka 2016. Bandung: Badan Pusat Statistik Provinsi Jawa Barat.

BP3K Kecamatan Sukabumi. 2017. Programa Penyuluhan Pertanian Kecamatan Sukabumi 2017. Sukabumi: BP3K Kecamatan Sukabumi.

Direktorat Budidaya dan Pascapanen Florikultura. 2015. Standar Operasional Prosedur (SOP) Pascapanen Dracaena (Daun Potong). Jakarta: Direktorat Budidaya dan Pascapanen Florikultura.

Direktorat Jenderal Hortikultura. 2013. Pedoman Teknis Peningkatan Produksi, Produktivitas dan Mutu Produk Hortikultura Berkelanjutan Tahun 2014. Jakarta: Direktorat Jenderal Hortikultura.

2015. Statistik Produksi Hortikultura Tahun 2014. Jakarta: Direktorat Jenderal Hortikultura.

Henni Kristina Tarigan. Florikultura Indonesia 2017. http://hortikultura.pertanian.go.id. (diakses 15 Oktober 2017).

Jamalludin. 2019. Analisis Efisiensi Ushatani Sayur-Sayuran Di Kelurahan Maharatu Kecamatan Marpoyan Damai Kota Pekanbaru. Jurnal Agribisnis Vol: 21, 88-99.

Li, L. P. 2000. Yield Gaps, Economic Inefficiency and Potential for Productivity Growth of Rice Farms in China [Dissertation]. Philippines: University of the Philippines.

Mufriantie, Fithtri., Anton Feriady. 2014. Analisis Faktor Produksi dan Efisiensi Alokatif Usahatani Bayam (Amarathus Sp) di Kota Bengkulu. Jurnal Agrisep Vol. 15, No. 1, Universitas Unsyiah.

Nicholson, Walter. 2002. Mikroekonomi Intermediate. Edisi Kedelapan. Erlangga. Jakarta.

Safwan, M., Muani, A., dan Suyatno, Adi. 2016. Analisis Alokasi Penggunaan Faktor-faktor Produksi dalam Upaya Pengembangan Agribisnis Lidah Buaya di Kota Pontianak. Jurnal Social Economic of Agriculture. Volume 5 No. 2: 21-27.

Soekartawi. 2003. Teori Ekonomi Produksi dengan Pokok Bahasan Analisis Fungsi Cobb-Douglas. Cetakan Ketiga. Jakarta: Rajawali Pers.

Sundari, M. T. 2011. Analisis Biaya dan Pendapatan Usahatani Wortel di Kabupaten Karanganyar. Solo: Jurnal Sosial Ekonomi Pertanian dan Agribisnis. 7(2):119-126.

Suprapti, Isdiana, Dwidjono Hadi D, Jangjung H M, Lestari R W. 2014. Efisiensi Produksi Petani Jagung 
Madura dalam Mempertahankan Keberadaan Jagung Lokal. Jurnal Agroekonomika, ISSN 9-772301994005 Volume 3 No. 1: 11-20.

Tamam, D. dan Soedjatmiko U. 2006. Taman Hias Mini. Jakarta: Penebar Swadaya.

Tinaprilla, N. 2012. Efisiensi Usahatani Padi Antar Wilayah Sentra Produksi di Indonesia: Pendekatan Stochastic Metafrontier Production Function
[Disertasi]. Bogor: Institut Pertanian Bogor.

Wahida, Made Antara, Rustam Abd. Rauf. 2015. Efisiensi Penggunaan Input Produksi Pada Usahatani Bawang Merah Varietas Lembah Palu Di Desa Bulupountu Jaya Kecamatan Sigi Biromaru Kabupaten Sigi (Studi Kasus Di Desa Bulupountu Jaya, Kecamatan Sigi Biromaru, Kabupaten Sigi). Jurnal Agroland 22 (1): 57-68. 